\title{
OJAČAVANJE LOKALNOG PUTA VIZIĆ-ERDEVIK SA GEOMREŽAMA
}

\author{
Miloš Šešlija ${ }^{1}$ \\ Igor Peško ${ }^{2}$ \\ Nebojša Radović ${ }^{3}$ \\ Milan Trivunić ${ }^{4}$ \\ Dragana Bibić $^{5}$
}

УДК: 624.138:625.711.1

Rezime: Lokalni put Vizić- Erdevik povezuje dve regije Srem i Back konekcija između dve regije je dužine oko $21 \mathrm{~km}$, dok je veza preko predmetne deonice približno $7.5 \mathrm{~km}$. Ovaj put se nalazi u ravničarskom predelu i ukupna širina voznih traka iznosi svega $4 \mathrm{~m}$. Postojeći kolovoz na trasi je većim delom od tucanika (frakcije $4 / 32 \mathrm{~mm}$ ) i prilikom atmosferskih padavina dolazi do ispiranja zrna agregata $i$ slabljenja površine kolovoza pri čemu dolazi do pojava oštećenja u vidu rupa i denivelisanih površina kolovoza koje dovode do smanjene prohodnosti putničkih vozila. Da bi se smanjila oštećenja tucaničkog sloja koristimo geomreže, koje drže zrna agregata uklještena $i$ ne dozvoljavaju da se pomeraju. Upotreba ovih geomreža doprinosi prohodonosti i ojačanju kolovozne površine. Cilj rada jeste prikaz korišćenja geomreža na lokalnim putevima radi ojačanja i smanjenja troškova korisnika puta.

Ključne reči: lokalni put, geomrě̌e

\section{UVOD}

Lokalni put je javni put koji povezuje teritorije dve opštine, ili naseljena mesta na području opštine. Lokalni put je značajan za saobraćajnu povezanost naselja unutar opštine. Izgradnju i održavanje lokalnih puteva vrši opština na čijoj se teritoriji nalazi lokalni put [1].

\footnotetext{
${ }^{1}$ Miloš Šešlija, mast. inž. građ., University of Novi Sad, Faculty of Technical Sciences, Trg Dositeja Obradovića 6, Novi Sad, Serbia, tel: +381 6539900 89, e - mail: slavijasrb@gmail.com

${ }^{2}$ Doc. dr Igor Peško, mast. inž. građ., University of Novi Sad, Faculty of Technical Sciences, Trg Dositeja Obradovića 6, Novi Sad, Serbia, tel: +381 6310289 11, e - mail: igor.pesko@gmail.com

${ }^{3}$ Prof. dr Nebojša Radović, dipl. inž. građ., University of Novi Sad, Faculty of Technical Sciences, Trg Dositeja Obradovića 6, Novi Sad, Serbia, tel: +381 6544059 00, e - mail: radovic.nebojsa62@gmail.com

${ }^{4}$ Prof. dr Milan Trivunić, dipl. inž. građ., University of Novi Sad, Faculty of Technical Sciences, Trg Dositeja Obradovića 6, Novi Sad, Serbia, tel: +381 6310285 11, e-mail: trule@uns.ac.rs

${ }^{5}$ Dragana Bibić, mast. inž. građ., University of Novi Sad, Faculty of Technical Sciences, Trg Dositeja Obradovića 6, Novi Sad, Serbia, tel: +381 6910828 90, e - mail: draganama@msn.com
} 


\section{$41^{\text {th }}$ ANNIVERSARY FACULTY OF CIVIL ENGINEERING SUBOTICA}

International conference

Contemporary achievements in civil engineering 24. April 2015. Subotica, SERBIA

Predmetna deonica se nalazi delom na sremskoj strani opštine Bačka Palanka, a delom na području opštine Šid, između naselja Vizić i Erdevik u ukupnoj dužini od $7.5 \mathrm{~km}$ (a deonica koja je od tucanika, dužine 4.818,88m) (slika 1.).

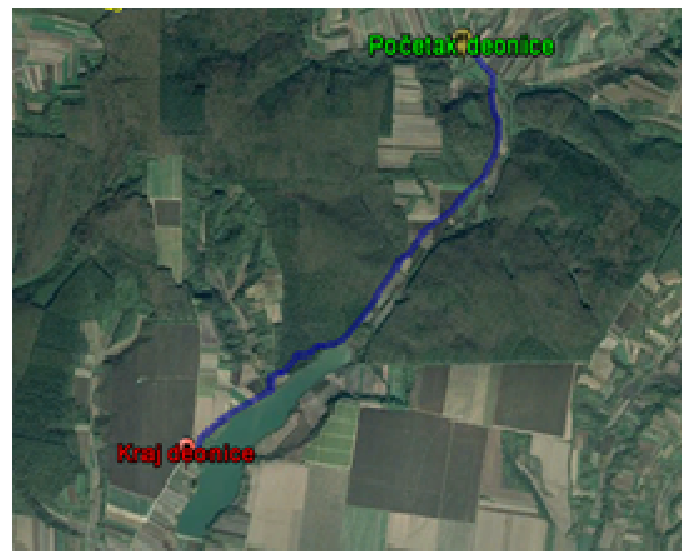

Slika 1. Predmetna deonica Vizić-Erdevik

Cilj istraživanja se sastoji na ojačanjem geomrežama na lokalnom putu za predmetnu deonicu.

\section{GEOMREŽE}

Geomreže za ojačanje putne infrastrukture i terena sadrži proizvode čija je primarna namena ojačanje infrastrukturnih objekata kao što su putevi, aerodromske piste, parkinzi, pruge i svi tereni preko kojih je frekventan saobraćaj i koji trpe veliki pritisak usled tereta. Uz pomoć ovih proizvoda vrši se kako ojačavanje putnog sloja (asfalta, betona, zemlje) tako i ujednačavanje prenošenja pritiska na podlogu i povećavanje površine na koju pritisak deluje (slika 2.), tako da sprečava pojavljivanje deformacije podloge (kao npr. kolotrazi na putu). Takođe se koriste i kod ojačavanja veštačkih bedemova napravljenih kako bi se sprečila erozija zemljišta i klizišta [2].

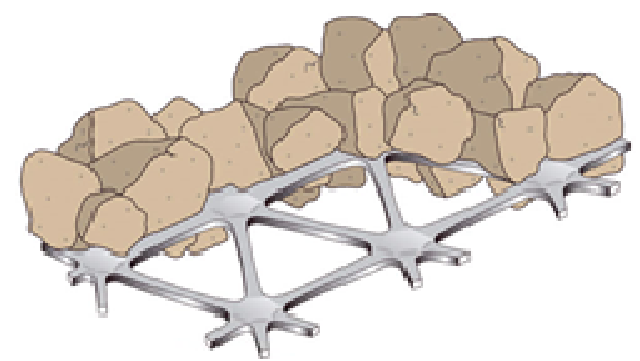

Slika 2. Uklještene zrna agregata pomoću geomreža 


\section{ANALIZA POSTOJEĆEG STANJA I OPRAVDANOST IZGRADNJE PREDMETNE DEONICE}

Postojeća deonica predstavlja atarski put između sela Vizić i sela Erdevik, dakle ne postoji asfaltni zastor. Obilaskom trase je utvrđeno da drobljeni kamen nije nasut na celoj dužini deonice. Na prvih 500m deonice nije izvršeno nasipanje drobljenog kamena i praktično na tom delu je put neprohodan izuzev za poljoprivrednu mehanizaciju (slika 3.).

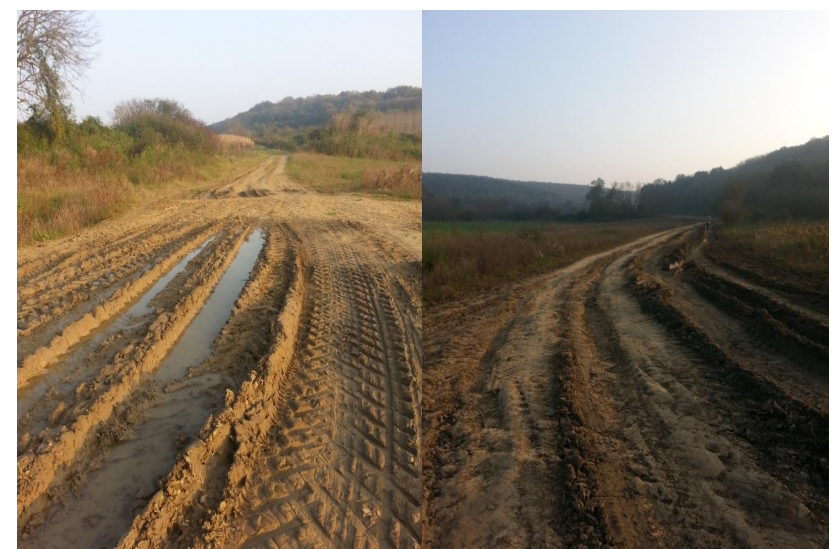

Slika 3. Postojeće stanje deonice od km 0+000.00 do km 0+500.00

Nakon stacionaže km 0+500.00 izvršeno je nasipanje drobljenog kamena sve do km $2+200.00$, dok od stacionaže $\mathrm{km} 2+200.00$ do $\mathrm{km} \mathrm{3+200.00} \mathrm{nije} \mathrm{izvršeno} \mathrm{nasipanje}$ drobljenog kamena. Od stacionaže km 3+200.00 do km 4+818.88 izvršeno je nasipanje drobljenog kamena (slika 4.), a od km $4+818.88$ pa do kraja je asfaltni kolovoz. Sirina postojećeg atarskog puta varira duž deonice. Usvojeno je da je prosečna širina puta $4.0 \mathrm{~m}$.

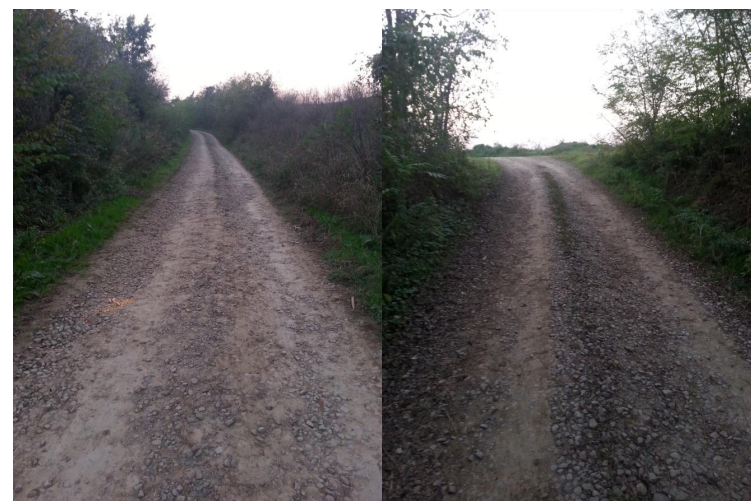

Slika 4. Postojeće stanje deonice od $\mathrm{km} \mathrm{3+200.00} \mathrm{do} \mathrm{km} \mathrm{4+818.88} \mathrm{km}$ 
$\mathrm{Na}$ osnovu analize prikazanog postojećeg stanja zaključeno je da je predmetna deonica neprohodna, izuzev poljoprivredne mehanizacije, i na delu od 2+200,00 do 3+200,00 $\mathrm{km}$, dakle na onim deonicama gde nije izvršeno nasipanje drobljenog kamena. Takođe je zaključeno i da je nasuti sloj drobljenog kamena na velikom delu deonice u dosta lošem stanju, odnosno da je neophodno izvršiti radove na saniranju postojećeg sloja. Predmetna deonica predstavlja jedinu dirketnu vezu dve opštine (Bačka Palanka - Šid). Postojeća konekcija dve opštine je put Erdevik - Bingula - Divoš - Vizić što prelazi preko opštine Sremska Mitrovica i ukupna dužina je približno $21 \mathrm{~km}$, dok je veza preko predmetne deonice ukupne dužine približno 7,5 km što predstavlja značajno skraćenje (slika 5.).

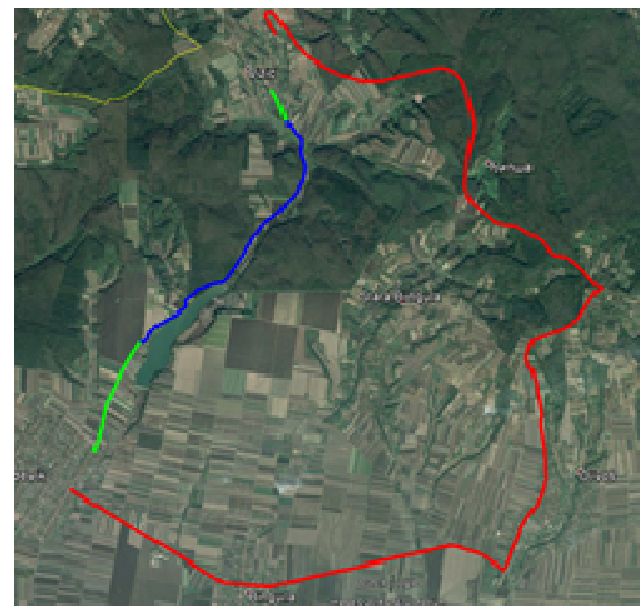

Slika 5. Prikaz postojeće veze Vizić-Erdevik i veze preko predmetne deonice

Na slici 5 je prikazana postojeća veza između naselja Vizić i Erdevik (crveno). Takođe prikazana je i veza pomenuta dva naselja preko predmetne deonice (plavo). Predmetna deonica se nadovezuje na postojeće asfaltirne kolovoze koji su obeleženi zelenom bojom. Dakle jasno je da se izgradnjom predmetne deonice značajno skraćuje direktna veza između dva naselja i dve opštine.

Pored prikazane koristi u vidu skraćenja direktne veze, izgradnja predmetne deonice će dovesti do povećanja turističke atraktivnosti užeg regiona oko jezera, što će prouzrokovati i veće dnevne seozenske migracije lokalnog stanovništva pomenutih naselja, ali i šireg regiona opštine Bačka Palanka i okolnih opština.

\section{ZAKLJUČAK}

Značaj izgradnje predmetne deonice se ogleda kako u povezivanju stanovništva sela Vizića sa selom Erdevik u opštini Šid tako i u razvoju ovog dela opštine Bačka Palanaka i opštine Šid ako se uzme u obzir sve veća atraktivnost ovog regiona sa aspekta voćarstva i vinogradarstva. Takođe ovaj region je sve atraktivniji i sa spekta formiranja vikend naselja, a izgradnja predmetne saobraćajnice bi još više doprinela tome ako se

\section{6}


uzme u obzir neposredna blizina jezera. Upotrebom geomreža dovodi do poboljšanja lokalnog puta i smanjenja troškova korisnika. Ovakav vid korišćenja geomreža se naziva armianje zemlje čime se povećava veća nosivost date trase. Pošto se radi o lokalnom putu koji jako mali broj ljudi zna, upotreba geomreža bih se ekonomski isplatilo za korsnike između dva seoska naselja (Vizić-Erdevik). Izgradnjom asfaltnog kolovoza ne bih bilo opravdano sa ekonomske strane za naredni period od 20 godina, ali za neki veći period možda bih se isplatila izgradanj ovog tipa lokalnog puta.

U suprotnom ako bi došlo do povećanjog obima saobraćaja u ovim opštinama zbog prirodnog bogadstva, tj. jezera, ekonomska isplatljivost za izgradnju fleksibilnog kolvoza bi se isplatila i bila bi veoma zadovoljavajuća sa aspekta korišćenja korisnika.

Ekonomska opravdnost se ogleda i u održavanju lokalnog puta koja je potrebna (slika 6.). Za sve vrste puteva ekonomska opravdanost je ista.

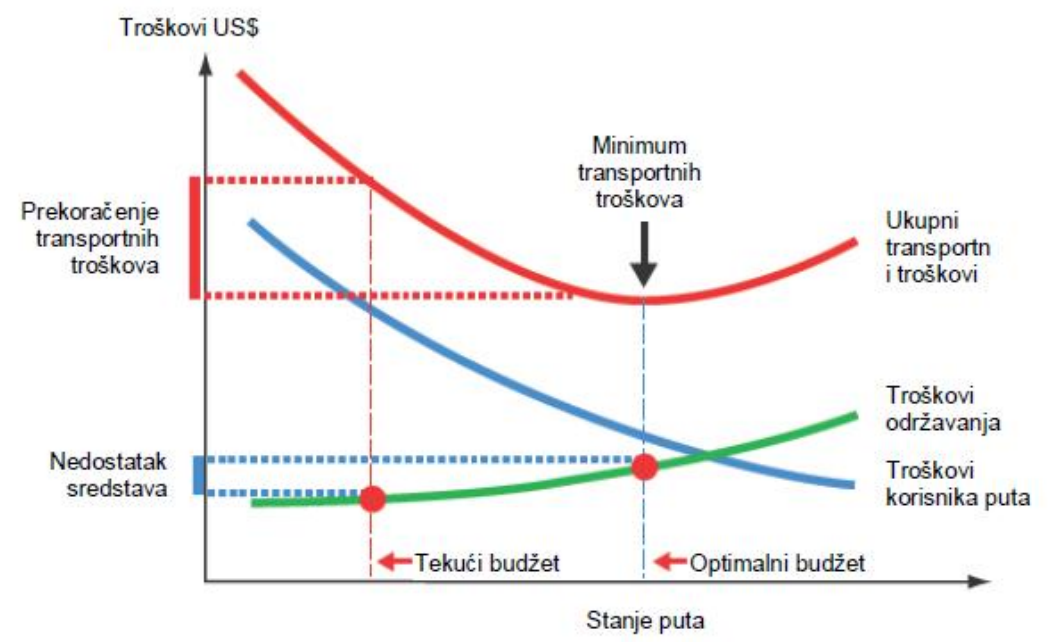

Slika 6. Odnos između troškova korisnika puta i troškova održavanja-ulaganja u putnu mrě̌u [3]

Ako se put ne održava adekvatno svaki US \$ koji se ne uloži u održavanje generalno povećava operativne troškove vozila za 2-3 US \$. Stoga, kao što je prikazano na slici 6 , manja ulaganja u održavanje puta povećavaju transportne troškove u putnom prometu i neto troškove za upravljanje u celini.

\section{ZAHVALNOST}

U radu je prikazan deo istraživanja koje je pomoglo Ministarstvo za nauku i tehnološki razvoj Republike Srbije u okviru tehnološkog projekta TR 36017 pod nazivom: "Istraživanje mogućnosti primene otpadnih i recikliranih materijala u betonskim 
kompozitima, sa ocenom uticaja na životnu sredinu, u cilju promocije održivog građevinarstva u Srbiji".

\section{REFERENCES}

[1] Cvetanović, A., Banić, B.: Lokalni putevi, Akademska misao, Beograd, 2013.

[2] http://www.tecasi.co.rs/proizvodi/tema/geo_mreze/za ojacane putne infrastrukture. html, pregledano 20.02.2015.

[3] Radović, N., Šešlija, M., Peško, I.: Ekspertne projektne analize u procesu gospodarenja održavanjem cesta, Građevinar, 2013., 65, vol 7., p.p 641-652.

\section{REINFORCEMENT LOCAL ROAD VIZIĆ-ERDEVIK WITH GEO GRID}

Summary: Local road Vizić - Erdevik connects two regions, Srem and Bačka. Existing road connection between the two regions is approximately $21 \mathrm{~km}$ in length, while the connection over the mentioned route is approximately $7.5 \mathrm{~km}$. This road is located in the lowlands and the total width of the drive lanes is only $4 \mathrm{~m}$. The existing driveway on the route is mostly of crushed stone (fraction $4 / 32 \mathrm{~mm}$ ) and with atmospheric precipitation it comes to washing aggregate and weakening the road surface whereby the occurrence of damage in the form of holes and at-graded road surface, which leads to reduced mobility of passenger vehicles. In order to minimize the damage of crushed stone layer will be used so-called geo grids, which held the aggregate grain clamped and do not allow them to move. The use of these geo grids contributes mobility and reinforcement of the pavement surface. The aim of the paper is to present the use of geo grid on local roads for their reinforcing and reducing the cost of road users.

Keywords: local road, geo grids 